\title{
A Study on the Reform of Master's Cultivation Mode in the Major of Design in Local University: Centered on the Cultivating the Ability of National Cultural Innovation and Practice
}

\author{
Haifeng $\mathrm{Chu}^{*}$ \\ Guilin University of Electronic Technology School of Art \& Design, Guangxi, Guilin, China 541004 \\ *Corresponding author
}

\begin{abstract}
Taking the ability training of "national culture innovation and practice" as the core, this study discusses how to reform the cultivation mode for design professionals in local colleges and universities. This study explores the specific methods of personnel training mode reform from the aspects including the construction of training system with personnel characteristics, the integration of "national culture" and teaching content, the introduction of integration of production and education, the emphasis on science and education cooperation, the construction of teaching evaluation and quality assurance mechanism with characteristics. This study aims to explore personnel training in local university to support the local economic construction. At the same time, this study tries to create the personal characteristics of the major in design in local colleges and universities, leading to the goal of teaching reform to upgrade the traditional design specialty.
\end{abstract}

Keywords: National cultural innovation and practice, Local University, Training mode for intelligence,

Reform

\section{INTRODUCTION}

In the face of a series of national strategic development needs such as innovation driven development and "made in China 2025", the interdisciplinary integration of disciplines is not only the "patent" of engineering, but also the active participant of local construction in social, humanities and design disciplines. Therefore, the training of master's degree in the major of design in local comprehensive universities are also needed to combine the advantages of regional cultural resources; to pay attention to the needs of professional intelligence, and to complete the transformation and upgrading of the traditional training mode of master's degree in the major of design by school enterprise cooperation, integration of production and education, and collaborative education. Local colleges and universities need to actively build a model for training professional intelligence, teaching evaluation and quality assurance mechanism, which are characterized by "national cultural innovation and practice", in order to achieve the goal of training professional intelligence in local colleges and universities which would support local economic construction.

\section{THE CURRENT SITUATION OF TALENTS TRAINING PROFESSIONAL INTELLIGENCE OF DESIGN IN LOCAL COLLEGES AND UNIVERSITIES}

\footnotetext{
Through the investigation and discussion with the design front-line employers, it is understood that the employers need high-level compound talents with innovative and practical design capabilities. The "innovation ability" refers to the interpretation of national cultural innovation in the field of design. The "practical ability" includes the basic design ability and the corresponding design ability to meet Party A's professional needs. However, at present, the graduate students in the major of design in local colleges and universities pay attention to either theoretical research or practical ability. They have deficiency in the combination of those two abilities. Therefore, it is difficult for students to put into work immediately after graduation and grow into professional intelligence with independent design ability.
} 


\section{ISSUES FOR TRAINING STUDENTS WITH MASTER'S DEGREE OF DESIGN IN LOCAL COLLEGES AND UNIVERSITIES}

\subsection{A Lack of Interdisciplinary Integration in Master Training for Design}

In the training of master's degree in design, due to the lack of interdisciplinary integration, students' cultural "innovation ability" is insufficient. The teaching of design discipline involves the basic contents of history, society, culture and other disciplines. If only paying attention to the professional education of the major and discipline, it would cause a series of problems as follows. First, the students' research field is not wide; second, the research scope is narrow; and the research level is not deep. Those will eventually lead to the students' insufficient understanding of design and the lack of cultivation of students' design innovation ability.

\subsection{A Lack of Integration of Middle-class Education in Master Training for Design}

The lack of integration of middle-class education in the master of design leads to the lack of students' cultural "practical ability". It is not enough to focus on theoretical research in the training of master degree for design. Compared with the undergraduate education, the training of master degree for design ignores the process of the enterprise's teaching practice. Many of senior students pay attention to theoretical scientific research projects, which is insufficient in the cultivation and exercise of "practical ability".

\subsection{A Disconnection between Curriculum System and Cultural Innovation}

The disconnection between the curriculum system and the innovation of national culture in the training of master's degree for design leads to the students' poor understanding of "the connotation of national culture". In the process of study, graduate students majoring in design often fall into a mistake that only focusing on design skills, but ignoring exploring national culture. When students graduate, the ability of national culture innovation is insufficient; the content they learn is divorced from the demand of local talents, and the difficulty of employment is relatively increased.

\section{ON THE REFORM OF THE MASTER TRAINING MODE FOR DESIGN IN LOCAL UNIVERSITIES}

\author{
4.1. Training Mode of "National Culture \\ Innovation and Practice" to Enhance \\ Students' Capability and Promote the \\ Transformation and Upgrading of Traditional \\ Design Specialty
}

The enrollment and training of students pursuing master's degree in design include specialities in industrial design, environmental design, visual communication design, digital media design, clothing design and other professional directions. Taking the educational concept of "national culture research" as the basis of master's training for design, we can break the professional barriers in training, guide teachers and students to broaden their perspectives, treat design major from a higher level of national culture, and break the concept of focusing only on their own professional design ability, and comprehensively introduce national culture into the overall educational concept of master's training of design major. It could effectively guide students to learn and understand the national cultural background and actual needs of the project in the research of different national design projects, and apply the "national culture" to the "teaching" and "learning" of graduate design education.

\subsection{Training Mode of "National Culture Innovation and Practice" to Establish a Team of Interdisciplinary Graduate Tutors}

In the training of master's degree for design, the traditional training mode is mostly guided by tutors while students learn it passively; or a teaching team with tutors from the same major leads students to study and research. In the postgraduate training stage, the design discipline doesn't not only aim at training the design ability with a single specialty, but also at the comprehensive research ability training with Pan specialty from the cultural level. In certain degree, the single tutor training mechanism can not provide graduate students with a broader knowledge soil. Therefore, it's benefit for students to improve the research pattern, the comprehensive ability and quality of pan specialty to take the education concept of "ethnic culture research" as the training penetration line, introduce enterprise tutors and build a multi-disciplinary master tutor team. 


\subsection{Construct Teaching System with Characteristics on the Basis of Interdisciplinary Graduate Tutor Team}

In teaching graduate students, we should break through the shackles of traditional and single teaching pattern. Under the leadership of an interdisciplinary tutor team, the multi-disciplinary and multi perspective exploration guided by the research projects of national culture would lead the students to participate in the specific design of local and actual projects in the way of team cooperation. Through the guidance of the tutor team and the in-depth cooperation between the school and the enterprise, the actual design projects are selected to complete the design research on the excavation of national culture, the innovation design of national culture, the practice design of national characteristics, etc. according to the specific projects; the team research methods of project division and group cooperation are adopted to understand the significance of "national culture research" in the project. Based on the actual research projects, the integration of production, education, school enterprise cooperation and collaborative education should be implemented. Based on that, the teaching system with characteristics should be constructed, and the teaching scheme with characteristics should be formulated to meet the needs of local design enterprises for professional intelligences.

\subsection{Focus on the Cultivating Students' Ability of "National Culture Innovation" on the Basis of "National Culture research"}

It has become the industry consensus of master's education and training of design specialty that taking "innovation" education as the core in training. For the cultivation of master's degree in general design, "innovative" design mainly focuses on the innovation of design form and design method. The cultivation of graduate students' ability with "national culture innovation" has been promoted from a single form of design innovation to a higher level of "national culture innovation". Based on the interdisciplinary tutor team, with guided by local ethnic projects, multi-disciplinary and multi-disciplinary cooperation, we would guide the core of culture in students' research from the perspective of ethnic culture with multiple perspectives and levels. In the training of master's degree for design, we try to make students have the design research consciousness of "national culture innovation" at the level of design theory.

\subsection{Focus on the Cultivating Students' Ability of "National Culture Practice" on the Basis of "National Culture Research"}

In essence, design is a comprehensive study of multi-disciplinary cooperation, which requires designers to have both innovation ability and practice ability. In the aspect of master's training for design, it is not enough to only cultivate students' innovation ability. When we cultivate students' ability of "national culture innovation", we should also concentrate to cultivating students' ability of "national culture practice". It should include not only theoretical research at the level of national culture, but also practical ability of "landing" design projects. The completion of a design project requires multi-disciplinary cooperation, mutual reference, and exploring specific ways and paths to achieve national projects. As result, students can complete the practical transformation from theory to practice at the realization level in design, and obtain the design and research ability of "national culture practice".

\subsection{Cultivate the Ability of "National Cultural Innovation and Practice" to Construct a System for Evaluate and Assurance Teaching Quality}

The training of "national culture innovation and practice" with characteristics is regarded as the basis of system for evaluate and assurance teaching quality in teaching students in the master of design. The evaluation of students' curriculum performance is based on the idea of "national culture" and "national cultural innovation and practical ability" instead of evaluating original simple design ability. The evaluation of specific course can be comprehensively assessed by the interdisciplinary graduate tutor team and the enterprise tutor team, the students and the "innovation and practice" ability of students.

In the construction of a system for evaluate and assurance teaching quality, on the basis of the characteristics with cultivating the ability of "national culture innovation and practice", the results from innovation and practice should be summarized and evaluated. We should ensure the teaching quality and take into account the characteristics of the discipline and specialty. Moreover, we should manage the process and target in the training system for professional intelligences. In the process of managing the process, the college should organize teaching supervisors to attend classes, evaluate courses and make peer reviews in order to guarantee the quality. For manage the goal, we invite many subjects (including enterprise tutors, interdisciplinary tutor teams and students) to evaluate the practical results of ethnic cultural design, and finally verify the teaching results. We manage teaching process and goal at the same time in order to construct an effective system for evaluate and assurance teaching quality in master education for the major of design.

\section{CONCLUSIONS}

During exploring the reform of postgraduate training system for the major of design, training the ability of "innovation and practice of national culture" is the core in local colleges and universities. It is conducive to promote 
traditional design major to upgrading and highlight the characteristics of talent training. In the process of cultivate professional intelligences in the major of design in local colleges and universities, it is necessary to for students emphasize the design research and ability of "national culture" in practice, and cultivate comprehensive ability for professional intelligences in the major of design, in order to meet the local needs. That will become the direction to reform master's cultivation mode in the major of design in local university.

\section{ACKNOWLEDGEMENT}

This research was financially supported by 2019 Innovation Project of Guang $\mathrm{Xi}$ Graduate Education $<<$ Research on the master's training mode of design specialty with the characteristics of "national cultural innovation and practice" ability training in Guangxi comprehensive colleges and Universities under the background of new engineering>> (Project Number: JGY2019081); 2018 Humanities and social sciences research project of the Ministry of Education $<<$ Study on the spatial memory and cultural heritage of historical streets in the protection of historical and cultural cities $>>1$ (Project Number: 18YJA760009), 2019 Graduate course construction project of Guilin University of Electronic Science and technology $<<$ Case base of residential protection and innovation design $>$ (Project Number: YKC201906).

\section{REFERENCES}

[1] Zheng Guiyu. Teaching Discussion on the integration of national cultural elements and packaging structure design [J]. Decoration, 2014 (10): 120-121

[2] Yang Maochuan, Guo Weimin, Ji Lin. training mode of research-oriented environmental design talents based on social resources -- Taking the Design Institute of Jiangnan University as an example [J]. Decoration, 2016 (07): 138-139

[3] Li Xiao, shangguanyi. Research on the education system of environmental art and design professionals [J]. Grand stage, 2013 (03): 231-232 